1. Delanoy, L. (1997?). Vegetation Survey of Natural Riverbank Lands North and West of the Regional Psychiatric Centre. Internal Document. Meewasin Valley Authority, Saskatoon, SK.

2. Fraser, W. P., and R. C. Russell. 1944. A Revised, Annotated List of the Plants of Saskatchewan. University of Saskatchewan, Saskatoon, SK.

3. Golder Associates Ltd., et al 1995. Peturrson's Ravine Management Plan. Report prepared for Meewasin Valley Authority.

4. Harms, V. L. 2000. Rare Native Vascular Plants of Saskatchewan. W.P. Fraser Herbarium, University of Saskatchewan, Saskatoon, SK.
5. Hudson, J. H. 1951-1987. Field journal notes (Saskatoon area abstracted). Unpublished.

6. Kartesz, J.T. 1999. A synonymized checklist and atlas with biological attributes for the vascular flora of the United States, Canada, and Greenland. First Edition. In: Kartesz, J.T., and C.A. Meacham (Eds.). Synthesis of North American Flora. Version 1.0. North Carolina Botanical Garden, Chapel Hill, NC.

7. Lineman, M. J. 1993. A Botanical Inventory of Some Natural Areas in the South Saskatchewan River Valley in and near Saskatoon. Part II - 1993 Site Surveys (Site 12). Report for Saskatoon Natural History Society and the Meewasin Valley Authority. Nov. 1993. 40 pp +126 pp. appendices.

\title{
PEZIZA PROTEANA VAR. SPARASSOIDES, AN UNUSUAL FUNGUS FOUND ON A FARM IN FISKE, SK
}

SUSAN KAMINSKYJ, Department of Biology, University of Saskatchewan, 112 Science Place, Saskatoon, SK S7H 2Z7. Email: Susan.Kaminskyj@usask.ca

In October 2000, Don Graham, who farms near Fiske, Saskatchewan, brought me a cream-coloured specimen of a fungus that looked superficially like a boiled cabbage (Figure 1). The sample weighed more than a kilogram, and had been broken off a much larger mass, probably at least four kilograms. It was not immediately clear what it was, but fortunately Don's wife Shirley had thought to freeze it - this is the best way to store fungal specimens until they can be preserved - and I was able to examine a piece under a microscope. It turned out to be the fruiting body of a type of ascomycete (a group that bears its spores in sacs called asci; Figure 2).

After discussing Don's find with experts in Edmonton, Prince George $\mathrm{BC}$, and Georgia (USA), the fungus was identified as Peziza proteana variety 


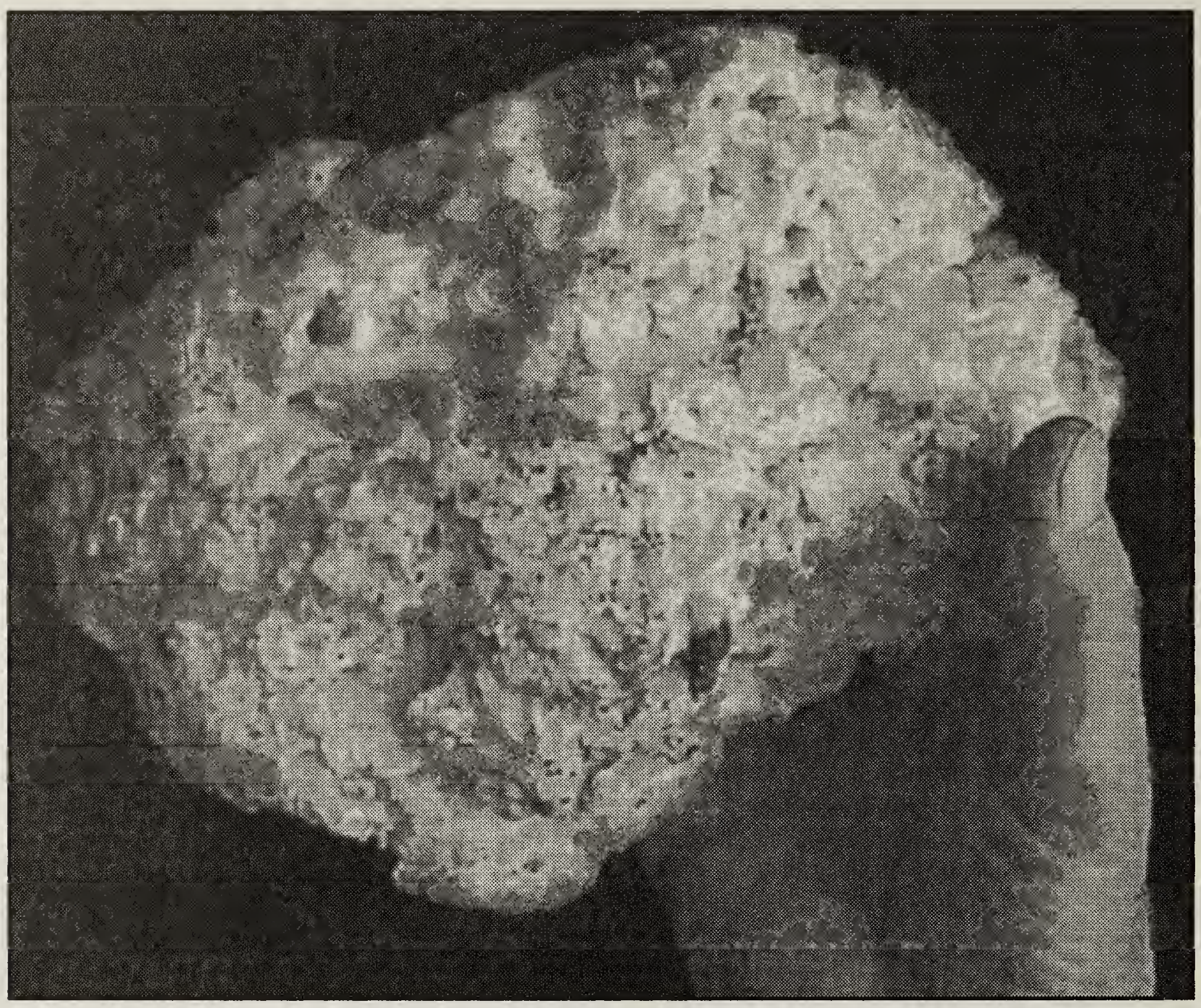

Figure 1. Peziza proteana var. sparassoides fruiting body

Dennis Dyck

sparassoides. Decoded, this name tells us quite a bit about the fungus: Peziza has cylindrical asci with starch in their tips (arrows in Figure 3); proteana means large fruiting body without a definite shape; sparassoides means resembling a type of basidiomycete called Sparassis. Indeed, Sparassis is sometimes called the cauliflower mushroom because of its shape and texture. Descriptive papers in the fungal literature, and a book containing descriptions of this species are available in the main library at the University of Saskatchewan. ${ }^{1,4,8}$

The story of where and how this fruiting body grew and was discovered is interesting, and characteristic of the species. In 1998, Don had plowed a Caragana / Manchurian Elm (Caragana arborescens / Ulmus pumila) hedgerow to control the elms that were spreading into his wheat fields. In the summer of 1999, he burned the 16 large piles of brush, creating fires so hot that they made clinkers in the soil. Later he partly buried the debris. The summer of 2000 was unusually wet (giant puffballs, genus Calvatia, were relatively common on his farm that year) and the $P$. proteana var. sparassoides was found fruiting within several of the loose piles of half buried, charred wood.

This specimen is interesting for several reasons. This is the first report of $P$. proteana var. sparassoides from Saskatchewan. ${ }^{2,3}$ Surprisingly, this species was not listed in a general North American ascomycete key, although it was in a key to Pacific Coast species. ${ }^{4,5,6,7}$ There are few large ascomycete species, and no others 


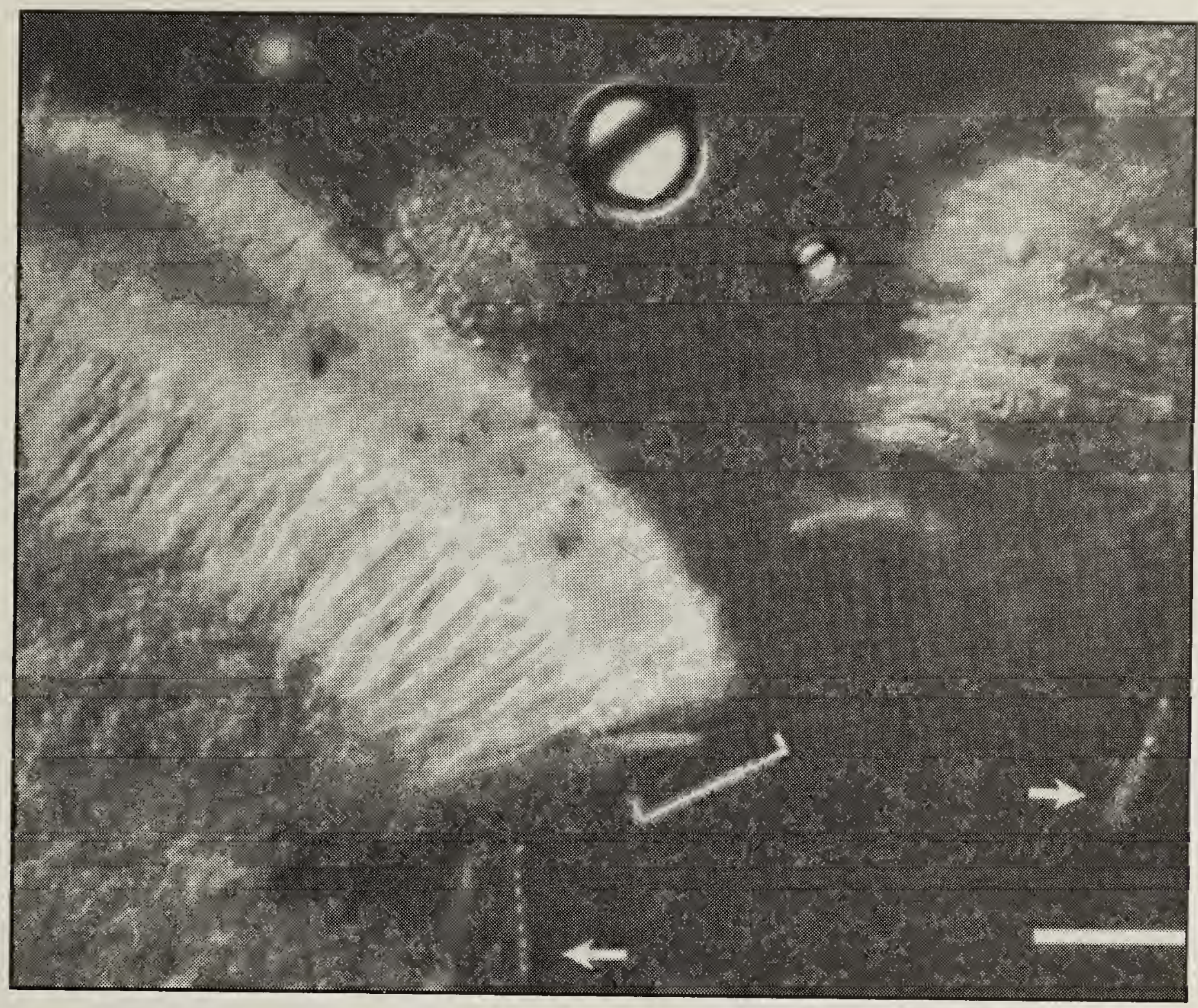

Figure 2. Freehand section across one of the lobes of the fruiting body. The surface has a layer (square bracket) of cylindrical, eight-spored asci (arrow). Bar $=0.1 \mathrm{~mm}$.

Susan Kaminskyj

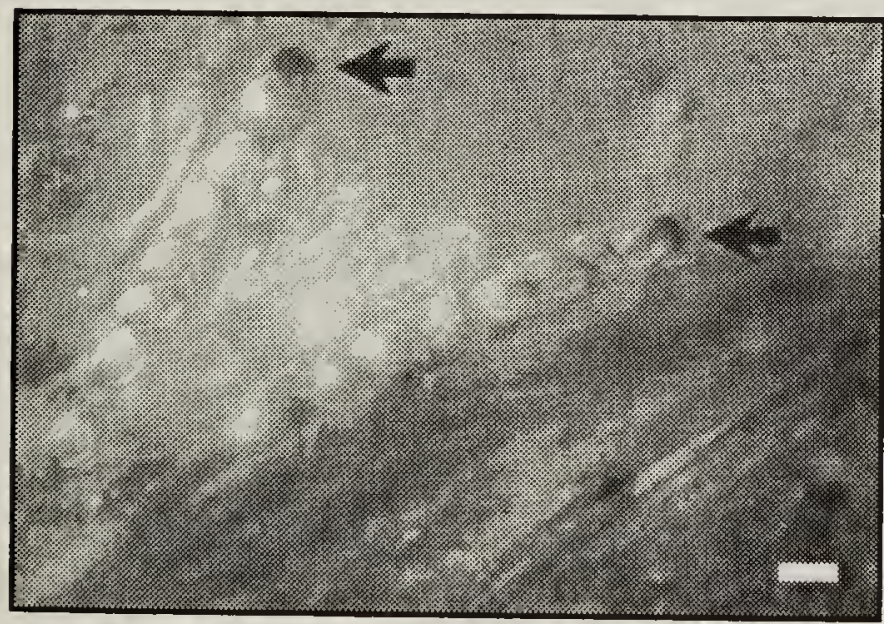

Figure 3. Asci stained with iodine have dark blue tips (arrow), indicating a high starch content. Bar $=10$ micrometres

Susan Kaminskyj

even a tenth this massive. Most ascomycete fruiting bodies are shaped like small cups, $0.5-5 \mathrm{~cm}$ in diameter. Morels are relatively large ascomycetes (up to about $15 \mathrm{~cm}$ tall) that superficially resemble mushrooms with "caps" of fused cups, but their fruiting bodies are hollow and very light. P. proteana var. sparassoides is large and solid and heavy, with a convoluted surface of solid lobes. On the piece shown in Fig. 1, there was no differentiation into sporebearing and support structures.

Some fungi grow preferentially on burned wood, including those called the "postfire ascomycetes", which could be important for helping to recycle trees after forest fires. ${ }^{9} \quad P$. proteana var. sparassoides must have been locally abundant in the soil for several of the burnt wood piles to be colonized, although the fire was probably sufficiently hot and long-lasting to have 
sterilized the soil at the immediate burn site. Given the current dry summer and all-too-frequent forest fires, the next year or so could be very good for finding this unusual species.

\section{Arora, D. 1986. Mushrooms Demystified:} a Comprehensive Guide to the Fleshy Fungi. Ten Speed Press, Berkeley

2. Bisby, G. R. 1938. The Fungi of Manitoba and Saskatchewan. National Research Council of Canada.

3. Bossenmaier, E. F. 1997. Mushrooms of the Boreal Forest. University Extension Press, University of Saskatchewan, Saskatoon

4. Durand, E. J. 1919. Peziza proteana var. sparassoides in America. Mycologia 11: $1-3$.
5. Hanlin, R. T. 1998. Combined Keys to Illustrated Genera of Ascomycetes, volumes I and II. APS Press.

6. Hanlin, R. T. 1990. Illustrated Genera of Ascomycetes, Volume I. APS Press.

7. Hanlin, R. T. 1990. Illustrated Genera of Ascomycetes, Volume II. APS Press.

8. Korf, R. P. 1956. Daleomyces, Duraniomyces, and other sparassoid forms of operculate discomycetes. Mycologia 48: 711-717.

9. Lumley, T. C., Gignac, L. D., Currah, R. S. 2001. Microfungus communities of white spruce and trembling aspen logs at different stages of decay in disturbed and undisturbed sites in the boreal mixedwood region of Alberta. Canadian Journal of Botany 79: 76-92.

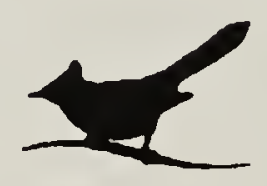

'Plover's origins are in the Latin pluvia, 'rain'. Most authorities agree on a hypothetical Latin form pluvarius for 'rain-bird', which gave rise to the Old French plovier, from which the English is derived. There are a number of myths about these shorebirds which suggest that they are easier to capture in the rain, or that their appearance heralds the rainy season. None of these is true."

Edward S. Gruson, Words for Birds :

A Lexicon of North American Birds with Biographical Notes. (p. 96) 